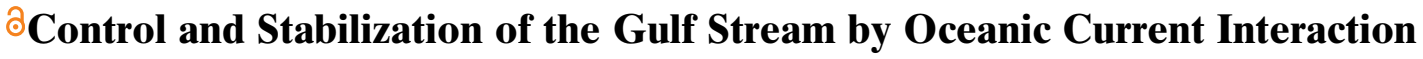 with the Atmosphere
}

\author{
LIONEL RENAULT \\ Department of Atmospheric and Oceanic Sciences, University of California, Los Angeles, Los Angeles, California

\section{JEROEN MOLEMAKER} \\ Department of Atmospheric and Oceanic Sciences, University of California, Los Angeles, Los Angeles, California, and \\ Laboratoire d'Ocanographie Physique et Spatiale, University of Brest, CNRS, IRD, Ifremer, IUEM, Brest, France \\ JONATHAN GULA \\ Laboratoire d'Ocanographie Physique et Spatiale, University of Brest, CNRS, IRD, Ifremer, IUEM, Brest, France \\ SEbastien Masson And James C. MCWilliams \\ Department of Atmospheric and Oceanic Sciences, University of California, Los Angeles, Los Angeles, California
}

(Manuscript received 9 May 2016, in final form 31 May 2016)

\begin{abstract}
The Gulf Stream (GS) is known to have a strong influence on climate, for example, by transporting heat from the tropics to higher latitudes. Although the GS transport intensity presents a clear interannual variability, satellite observations reveal its mean path is stable. Numerical models can simulate some characteristics of the mean GS path, but persistent biases keep the GS separation and postseparation unstable and therefore unrealistic. This study investigates how the integration of ocean surface currents into the oceanatmosphere coupling interface of numerical models impacts the GS. The authors show for the first time that the current feedback, through its eddy killing effect, stabilizes the GS separation and postseparation, resolving long-lasting biases in modeled GS path, at least for the Regional Oceanic Modeling System (ROMS). This key process should therefore be taken into account in oceanic numerical models. Using a set of oceanic and atmospheric coupled and uncoupled simulations, this study shows that the current feedback, by modulating the energy transfer from the atmosphere to the ocean, has two main effects on the ocean. On one hand, by reducing the mean surface stress and thus weakening the mean geostrophic wind work by $30 \%$, the current feedback slows down the whole North Atlantic oceanic gyre, making the GS narrower and its transport weaker. Yet, on the other hand, the current feedback acts as an oceanic eddy killer, reducing the surface eddy kinetic energy by $27 \%$. By inducing a surface stress curl opposite to the current vorticity, it deflects energy from the geostrophic current into the atmosphere and dampens eddies.
\end{abstract}

\section{Introduction}

The Gulf Stream (GS) is known to have a strong influence on the climate and the transport of heat from the tropics to middle and high latitudes. Understanding and

○ Denotes Open Access content.

Corresponding author address: Lionel Renault, Department of Atmospheric and Oceanic Sciences, University of California, Los Angeles, 405 Hilgard Ave., Los Angeles, CA 90095-1565.

E-mail: 1renault@atmos.ucla.edu modeling its mean path and variability is of uttermost importance for climate modeling. Upstream of Cape Hatteras the mean path is constrained by the topography (Gula et al. 2015) and is generally well understood and resolved by numerical models. However, at separationat Cape Hatteras and downstream-most models are characterized by large biases and too meandering a GS.

Satellite observations (e.g., AVISO; Ducet et al. 2000) reveal that the GS mean path position is stable and does not present a strong interannual variability (e.g., Fig. 1). On an annual time scale, the GS is characterized by a concave separation at Cape Hatteras; it then flows 


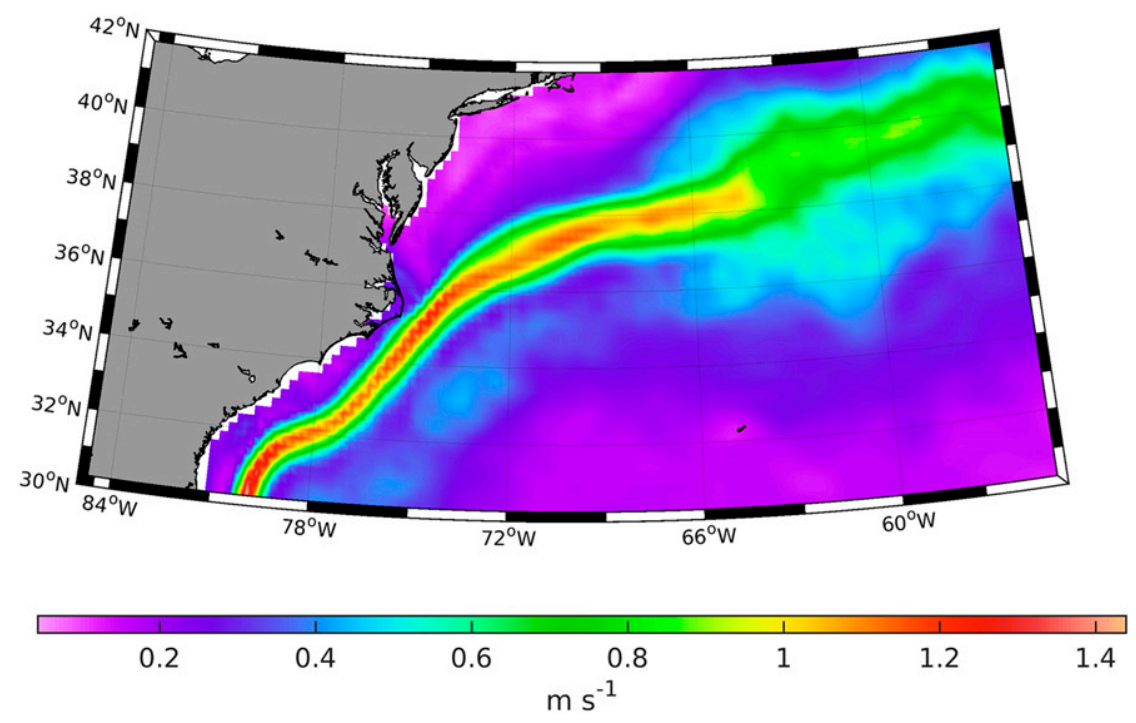

FIG. 1. The GS path stability illustrated by the RMS of the geostrophic current amplitude as estimated from AVISO over the period 1993-2013. Despite a significant interannual variability of its intensity, the GS path has a weak interannual variability, making it very stable.

eastward along a narrow path $(50 \mathrm{~km})$ without significant meandering. However, the GS transport has a clear interannual variability (e.g., McCarthy et al. 2012), which makes elusive the reasons why the GS path is stable. Recent advances in numerical ocean modeling have shown the importance of resolving the eddy scale while simulating the GS path and separation (Bryan et al. 2007; Chassignet and Marshall 2008; Talandier et al. 2014). Recently, Schoonover et al. (2016) confirmed the difficulties of numerical models to represent the mean GS separation and the postseparation stability using state of the art numerical simulations (across model platforms and resolutions). In particular, the vicinity of Cape Hatteras is erroneously marked by the presence of a standing eddy, making the GS separation convex. The reason for this sensitivity is not yet clear, although a strong link between GS separation and the strength and depth of the southward-flowing deep western boundary current has been shown (Spall 1996), and a minimum resolution of $1 / 10^{\circ}$ (Bryan et al. 2007; Chassignet and Marshall 2008) is deemed to be required for proper separation dynamics. A possible source of sensitivity is from the lack of current feedback to the atmosphere.

The ocean feedback to the atmosphere has been recently studied, mainly focusing on the thermal feedback (e.g., Chelton et al. 2004, 2007; Spall 2007; Perlin et al. 2007; Minobe et al. 2008; Park et al. 2006; Cornillon and Park 2001). Small et al. (2008) provides an interesting review of the different processes involved. Sea surface temperature (SST) gradients induce gradients in the lower-atmospheric stratification and hence gradients in vertical momentum flux in the atmospheric boundary layer. Gradients in the surface wind and stress are induced beneath an otherwise more uniform midtropospheric wind. Chelton et al. (2004, 2007), using satellite observations, showed approximately linear relationships between the surface stress curl (divergence) and the crosswind (downwind) components of the local SST gradient. Recent studies over the GS region also highlighted how a mesoscale SST front may have an impact all the way up to the troposphere (Minobe et al. 2008). Recently, Hogg et al. (2009), by using an ideal configuration of a high-resolution quasigeostrophic ocean model coupled to a dynamic atmospheric mixed layer, suggest small-scale variation in wind stress induced by oceanatmosphere interactions may modify the large-scale ocean circulation. The effect of oceanic currents is another aspect of the interaction between atmosphere and ocean; however, its effects are not yet well known. Some work showed that the current effect on the surface stress can lead to a reduction of the eddy kinetic energy (EKE) of the ocean via a "mechanical dampening" (Duhaut and Straub 2006; Dewar and Flierl 1987; Dawe and Thompson 2006; Hughes and Wilson 2008; Eden and Dietze 2009) and hence a reduction of the work done by the wind on the ocean (wind work). Yet, in those studies the atmospheric response to the current feedback is neglected. Recently Renault et al. (2016b) and Seo et al. (2016), using a coupled model, confirmed that the current feedback causes a reduction of the wind work, which in turn dampens the EKE. Renault et al. (2016b) demonstrated the current feedback-by inducing a surface stress curl of opposite sign to the current vorticitydeflects energy from the geostrophic current into the 
atmosphere and thus dampens eddies. However, the current feedback not only has an effect on the surface stress but also has a counteracting effect on the wind itself. The wind response counteracts the surface stress response. It decreases the offshore return of energy to the atmosphere, partially reenergizing the ocean.

Renault et al. (2016b) showed for the U.S. West Coast that the mean atmospheric and oceanic circulation and the mean wind work are not significantly impacted by the current feedback. However, this could be due to the weak oceanic mean dynamic of the U.S. West Coast. Scott and Xu (2009) and Hughes and Wilson (2008) showed that the lack of current feedback in the estimation of the surface stress can lead to an overestimation of the total energy input to the ocean by wind work and suggest that the current should be included when estimating the surface stress. In oceanic numerical models, this could lead to an overestimation of the energy input into the gyre and thus an overestimation of the GS transport intensity itself. In this paper, we use a set of atmospheric and oceanic coupled and uncoupled simulations and focus on the surface current feedback to the atmosphere. The objectives are to assess how the current feedback modifies the surface stress and wind work, and we address how it modulates the mean circulation and EKE over the North Atlantic basin. In particular, it aims to address whether the lack of current feedback in numerical models could explain the persistent biases in the GS separation and postseparation. In that sense, this study aims to understand to what extent the current feedback can improve the representation of the GS in numerical models.

The paper is organized as follows: Section 2 describes the model configuration and methodology. In section 3, the effect of the current feedback on the mean surface stress, mean wind work, and mean oceanic circulation is assessed. Section 4 addresses how the EKE is modulated by the current feedback. In section 5 , we show how the current feedback improves the mean path of the GS and its separation. The results are discussed in section 6 , which is followed by the conclusion.

\section{Model configuration and methodology}

The numerical models and configurations are similar to the ones employed in Renault et al. (2016b), and the following models descriptions are derived from there with minor modifications.

\section{a. The Regional Oceanic Modeling System}

The oceanic simulations were performed with the Regional Oceanic Modeling System (ROMS; Shchepetkin and McWilliams 2005; Shchepetkin 2015) in its Coastal and Regional Ocean Community (CROCO) version (Debreu et al. 2012). ROMS is a free-surface, terrainfollowing coordinate model with split-explicit time stepping and with Boussinesq and hydrostatic approximations. The main grid covers the full North Atlantic Gyre and Subpolar Gyre, extending from $0.4^{\circ}$ to $73.2^{\circ} \mathrm{N}$ and from $133.7^{\circ}$ to $21.7^{\circ} \mathrm{W}$ and is $1152 \times 1059$ points with a resolution of $6-7 \mathrm{~km}$.

As in Renault et al. (2016b), bathymetry is constructed from the Shuttle Radar Topography Mission global bathymetry and elevation data at $30 \mathrm{arcs}$ resolution with data voids filled (SRTM30_PLUS) dataset (available at http://topex.ucsd.edu/WWW_html/ srtm30_plus.html) based on the 1-min Sandwell and Smith (1997) global dataset and higher-resolution data where available. A Gaussian smoothing kernel with a width 4 times the topographic grid spacing is used to avoid aliasing whenever the topographic data are available at higher resolution than the computational grid and to ensure the smoothness of the topography at the grid scale. Also, to avoid pressure gradient errors induced by terrain-following coordinates in shallow regions with steep bathymetric slope (Beckmann and Haidvogel 1993), we apply local smoothing of the bottom topography where the steepness of the topography exceeds a factor $r=0.2$.

The domain is initialized using the Simple Ocean Data Assimilation (SODA) climatological state of 1 January and spun up for $14 \mathrm{yr}$ using climatological monthly surface fluxes and lateral oceanic boundary conditions (as in Gula et al. 2015; Renault et al. 2016b). It is then run for an additional period, from year 2000 to 2004, using interannual lateral oceanic forcing for the largest domain as well as interannual surface forcing for all simulations. Temperature, salinity, surface elevation, and horizontal velocity initial and boundary information for the domain are taken from the monthly averaged SODA ocean interannual outputs (Carton and Giese 2008).

In the coupled simulations the atmospheric fields are simulated using the Weather Research and Forecast (WRF) Model. The Fairall et al. (2003) bulk formulas are used to estimate the freshwater, turbulent, and momentum fluxes provided to ROMS. The very same atmosphere and bulk formulas are used in the uncoupled simulations.

The boundary condition algorithm consists of a modified Flather-type scheme for the barotropic mode and Orlanski-type scheme for the baroclinic mode (including temperature and salinity; Marchesiello et al. 2001). The domain has 50 levels in the vertical with a vertical grid system concentrating vertical levels near the surface (Shchepetkin and McWilliams 2009). The stretching surface and bottom parameters are $h_{\text {cline }}=300 \mathrm{~m}$, 
$\theta_{b}=2$, and $\theta_{s}=7$. Figure 2 of Lemarié et al. (2012) provides an example of the grid spacing for the stretching function used in Shchepetkin and McWilliams (2009) with a similar set of parameters. Finally, vertical mixing of tracers and momentum is done with a K-profile parameterization (KPP; Large et al. 1994).

\section{b. The Weather Research and Forecasting Model}

The WRF Model (version 3.7.1; Skamarock et al. 2008 ) is implemented in a configuration with one grid. The domain is slightly larger than the ROMS domain to avoid the effect of the WRF sponge (four points). It has a horizontal resolution of $20 \mathrm{~km}$. The model is initialized with the Climate Forecast System Reanalysis (CFSR) $(\approx 40-\mathrm{km}$ spatial resolution; Saha et al. 2010) from 30 December 1999 and integrated for $5 \mathrm{yr}$ with time-dependent boundary conditions interpolated from the same 6-hourly reanalysis; 40 vertical levels are used, with half of them in the lowest $1.5 \mathrm{~km}$, as in Renault et al. (2016a). The model configuration was setup with the following parameterizations: the WRF single-moment six-class microphysics scheme (Hong and Lim 2006), modified to take into account the droplet concentration (Jousse et al. 2016); the new Arakawa-Shubert cumulus parameterization (Han and Pan 2011); the new Goddard scheme for shortwave and longwave radiation (Chou and Suarez 1999); the Noah land surface model (Skamarock et al. 2008); and the Mellor-Yamada-Nakanishi-Niino (MYNN2.5) planetary boundary layer scheme (Nakanishi and Niino 2006).

\section{c. Experiments}

COUPLED is a SST and current coupled ROMSWRF simulation. Synchronized exchange of data fields between ROMS and WRF is handled via the Ocean Atmosphere Sea Ice Soil, version 3.0 (OASIS3), coupler (Valcke 2013). Every hour WRF gives ROMS the hourly averages of freshwater, heat, and momentum fluxes, whereas ROMS sends WRF the hourly SST and surface currents. The surface stress is estimated with a quadratic form using the bulk formulas described in Fairall et al. (2003):

$$
\boldsymbol{\tau}=\rho_{\text {air }} C_{D}|\mathbf{U}| \mathbf{U}
$$

where $\tau$ is the surface stress, $\rho_{\text {air }}$ is the air density, $C_{D}$ is the surface drag coefficient, and $\mathbf{U}$ is the wind used to estimate the surface stress. Here, the surface stress is estimated using a velocity that is the surface wind relative to the ocean surface current:

$$
\mathbf{U}_{r}=\mathbf{U}_{a}-\mathbf{U}_{o}
$$

where $\mathbf{U}_{a}$ and $\mathbf{U}_{o}$ are the surface wind (at the first vertical level in WRF) and the surface current (at the upper vertical level in ROMS), respectively.

UNCOUPLED is the ROMS uncoupled simulation that uses the configuration and atmosphere from COUPLED. It uses the first vertical level wind from COUPLED but does not take into account the oceanic surface current when estimating the surface stress. The SST feedback to the surface stress is taken into account in the bulk formulas using a stability function that depends on temperature and humidity gradients (Fairall et al. 2003).

\section{d. Wind work budget}

The numerical outputs for the solutions are daily averages. The mean $\overline{()}$ is defined with respect to long-term averaging (2000-04), and primes denote deviation from the long-term mean. The following quantities depend on both longitude and latitude. As in, for example, Stern (1975) and following closely the description in Renault et al. (2016b), the total wind work is defined as

$$
F K=\frac{1}{\rho_{0}}\left(\overline{\tau_{x} u_{o}}+\overline{\tau_{y} v_{o}}\right),
$$

where $u_{o}$ and $v_{o}$ are the zonal and meridional surface currents, $\tau_{x}$ and $\tau_{y}$ are the zonal and meridional surface stresses, and $\rho_{0}$ is mean seawater density.

The two main pathways of mechanical energy from the surface to the deeper ocean are wind forcing of near-inertial oscillations and wind forcing of surface geostrophic flows. Previous estimates of the wind power input to the oceanic general circulation (e.g., Wunsch 1998; von Storch et al. 2007; Scott and Xu 2009) use Eq. (3) and support the assumption that wind power to ageostrophic motions does not feed into the general circulation. In this study the oceanic simulations are forced by a high-frequency wind forcing (hourly) that produces large inertial oscillations and thus a large ageostrophic wind work that is not significantly impacted by the current feedback (Renault et al. 2016b). The current feedback causes a deflection of energy on the eddy time scale from the ocean geostrophic currents to the atmosphere. The current feedback effect on the geostrophic wind work and its consequences on the oceanic circulation is the focus of this study.

The oceanic geostrophic surface currents are estimated using the geostrophic approximation and the daily average sea surface height from the simulations:

$$
u_{o g}=-\frac{g}{f} \frac{\partial h}{\partial y},
$$



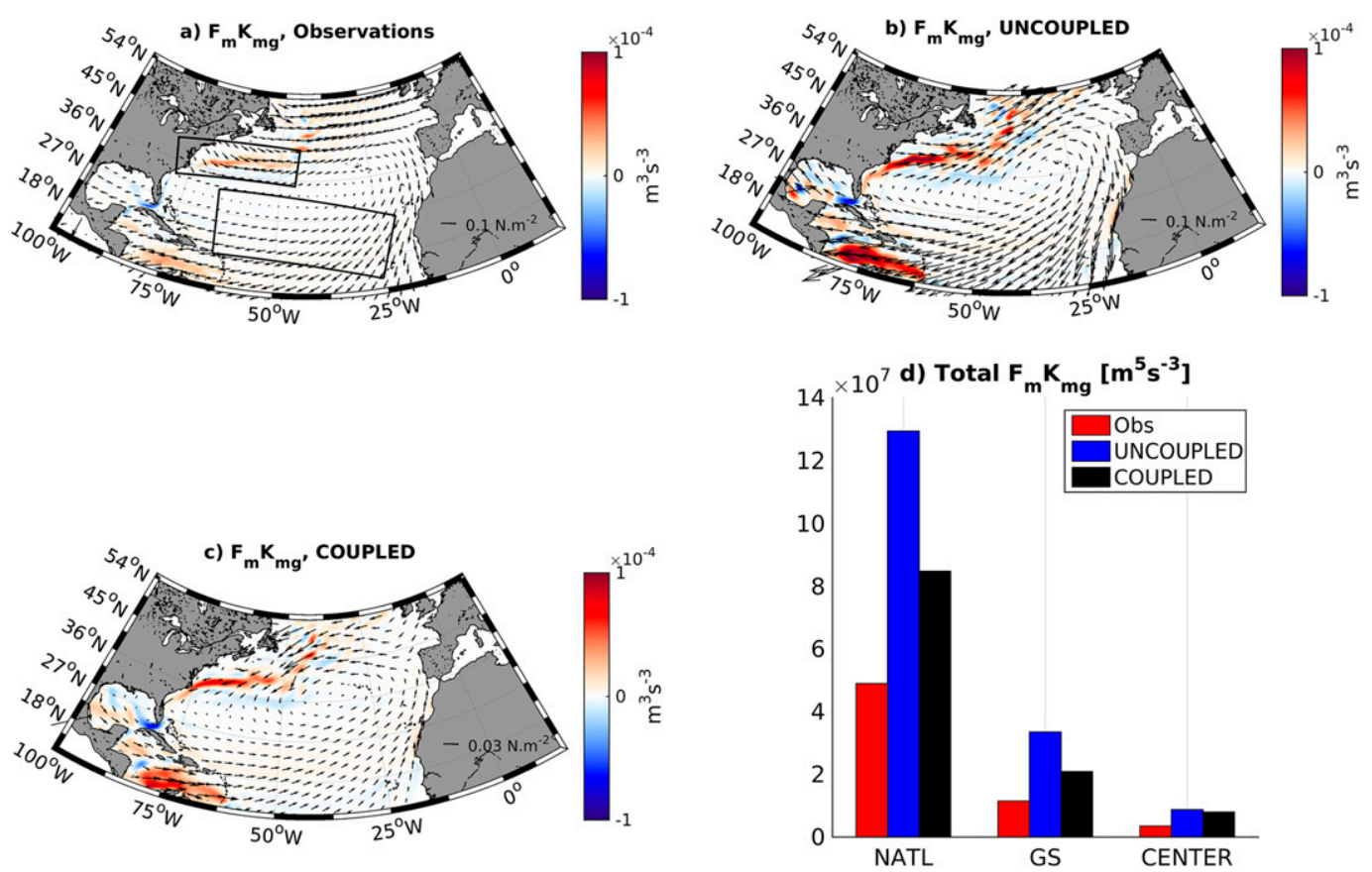

FIG. 2. Mean $F_{m} K_{m g}$ (colors) and surface stress (arrows) estimated from (a) the observations, (b) UNCOUPLED, and (c) COUPLED for the period 2000-04. In (c), the arrows represent the difference of mean surface stress between UNCOUPLED and COUPLED. (d) $F_{m} K_{m g}$ averaged over the whole domain (NATL), Gulf Stream (GS), and center of the domain (CENTER); see black boxes in (a). The current feedback to the atmosphere decreases the surface stress and reduces $F_{m} K_{m g}$ over the whole North Atlantic by $30 \%$.

and

$$
v_{o g}=\frac{g}{f} \frac{\partial h}{\partial x}
$$

where $u_{o g}$ and $v_{o g}$ are the zonal and meridional geostrophic currents, respectively; $g$ is the gravitational acceleration; $f$ is the Coriolis parameter; and $h$ is the daily average sea surface height from the simulation.

The oceanic surface currents can then be split into their geostrophic and ageostrophic parts:

$$
u_{o}=u_{o g}+u_{o a} \text {, }
$$

and

$$
v_{o}=v_{o g}+v_{o a} \text {, }
$$

with $u_{o a}$ and $v_{o a}$ as the zonal and meridional ageostrophic currents.

Substituting the decomposition of Eq. (6) into Eq. (3), the total wind work on the geostrophic flow is

$$
F K_{g}=\frac{1}{\rho_{0}}\left(\overline{\tau_{x} u_{o g}}+\overline{\tau_{y} v_{o g}}\right) .
$$

The term $F K_{g}$ can be split into its mean $F_{m} K_{m g}$ and eddy $F_{e} K_{e g}$ parts using a simple Reynolds decomposition that leads to

- the mean geostrophic wind work

$$
F_{m} K_{m g}=\frac{1}{\rho_{0}}\left(\overline{\tau_{x}} \overline{u_{o g}}+\overline{\tau_{y}} \overline{v_{o g}}\right),
$$

- the mean geostrophic eddy wind work

$$
F_{e} K_{e g}=\frac{1}{\rho_{0}}\left(\overline{\tau_{x}^{\prime} u_{o g}^{\prime}}+\overline{\tau_{y}^{\prime} v_{o g}^{\prime}}\right),
$$

and

$F_{m} K_{m g}$ represents the transfer of energy from the mean surface wind forcing to mean kinetic energy (KE). It is the main source of energy of the ocean at basin scale (Fig. 2 and, e.g., Scott and Xu 2009). The quantity $F_{e} K_{e g}$ represents the transfer of energy between the surface stress anomalies and the geostrophic currents.

\section{Current feedback large-scale impact}

The observed mean surface stress from the Scatterometer Climatology of Ocean Wind (SCOW; Risien and Chelton 2008) product is illustrated in Fig. 2a. The 

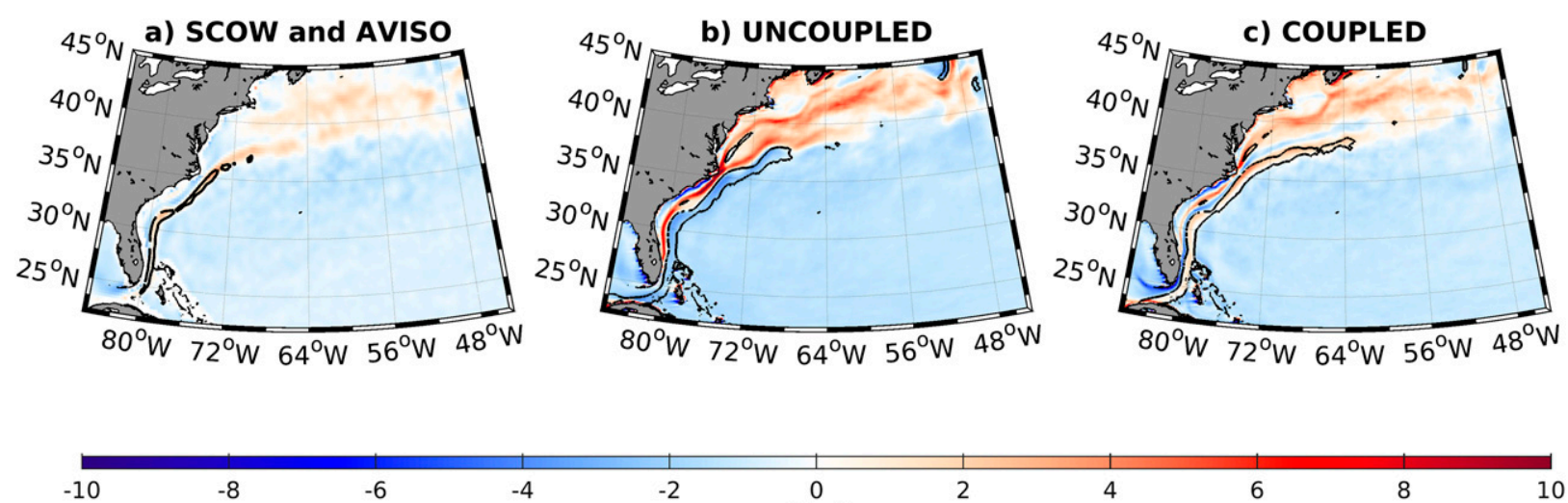

$-6$

$-4$

$-2$

0
$\mathrm{Nm}^{-3}$

2

4

FIG. 3. The colors represent the mean surface stress curl from SCOW and from UNCOUPLED and COUPLED (for the period 2000-04). The black contour shows the negative vorticity of the surface currents from AVISO and the simulations $\left(\right.$ contour of $\left.-3 \times 10^{-7} \mathrm{~m} \mathrm{~s}^{-1}\right)$. The current feedback weakens the large-scale surface stress curl and improves its realism. Because of the current feedback, the surface stress is decreased along the GS, inducing a positive surface stress curl collocated over the GS.

surface stress is driven by the mean atmospheric circulation that is characterized by the presence of westerly and easterly winds in the north and south of the North Atlantic basin, respectively. COUPLED and UNCOUPLED have the same wind (first vertical level in WRF) but not the same surface stress because COUPLED includes the effect of the ocean surface current to estimate it. COUPLED and UNCOUPLED have a good general representation of the mean surface stress; however, they both have a bias in the surface stress direction in the northwestern part of the domain, with a northward component overestimated with respect to the SCOW product (Fig. 2b). Because the mean currents are moving in the same direction as the wind, the current feedback reduces the mean surface stress up to $0.3 \mathrm{~N} \mathrm{~m}^{-2}$, where the currents are the strongest $\left[\boldsymbol{\tau}=C_{D} \rho_{a}\left(\mathbf{U}_{a}-\mathbf{U}_{o}\right)<C_{D} \rho_{a}\left(U_{a}\right)^{2}\right]$. The weakening of the surface stress is realistic and reduces the biases with respect to the SCOW product (Fig. 2c).

The presence of the GS has a very clear effect on the surface stress curl. The SST feedback to the atmosphere has been recently studied by, for example, Chelton et al. (2004), Spall (2007), and Minobe et al. (2008). Small et al. (2008) provides a review of the different mechanisms involved. For example, when weak winds cross a sharp front, the air temperature can equilibrate to SST. The air pressure response creates wind and surface stress anomalies near the front (Spall 2007). Chelton et al. (2004) highlight that wind stress curl is proportional to the crosswind SST gradient. In particular for the GS, Minobe et al. (2008) show how a mesoscale SST front may have an impact all the way up to the troposphere. Here, the focus is on the current feedback effect on the surface. By weakening the surface stress, in COUPLED, the current feedback reduces both the large-scale negative and positive stress curl with respect to UNCOUPLED, improving the realism of the simulation (Fig. 3). In UNCOUPLED, consistent with the literature, the SST feedback produces a band of positive surface stress curl that is situated westward of the GS path (Fig. 3b). There is an eastward positive SST gradient from the coast to the GS path (not shown). It induces a decrease of the surface stress (Chelton et al. 2004) and thus a positive stress curl, which is clearly overestimated with respect to SCOW (Fig. 3a). In COUPLED the SST feedback is still active. However, the current feedback produces an increase of the surface stress: the current vorticity is positive (Figs. 3a,b) and creates a negative surface stress curl (Renault et al. 2016b). It thus counteracts and then dampens the SST feedback effect, reducing the intensity of the positive band of surface stress curl along the U.S. East Coast. In the observations and in COUPLED along the GS path, there is a band of positive stress curl that is not present in UNCOUPLED. Here, again, because of the current feedback, the surface stress is decreased along the GS path (Figs. 3a,b), inducing a positive surface stress curl.

Figure 2 depicts the $F_{m} K_{m g}$ as estimated from the observations (using AVISO and SCOW) and the simulations. The larger $F_{m} K_{m g}$ values are situated along the westerly and easterly winds, where the current is also the strongest. Both COUPLED and UNCOUPLED reproduce the main spatial pattern of $F_{m} K_{m g}$. By weakening the large-scale surface stress, the current feedback induces a reduction of $F_{m} K_{m g}$ (Fig. 2), on average by $30 \%$. The main reduction occurs where the current is largest, that is, the southwestern 


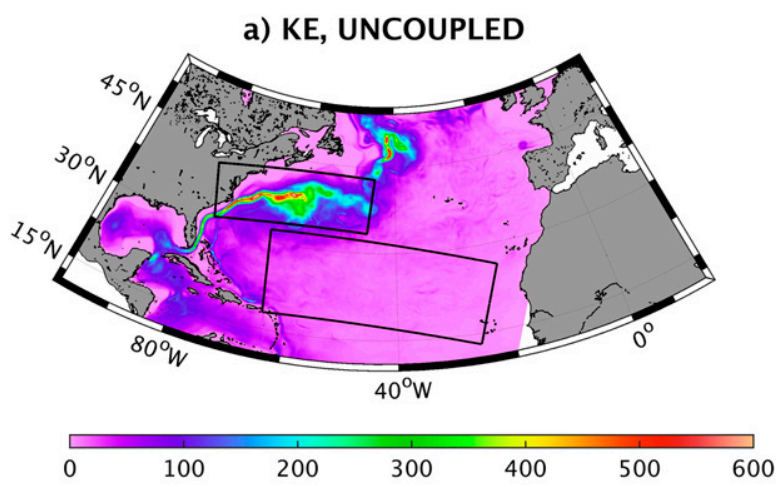

b) KE, COUPLED

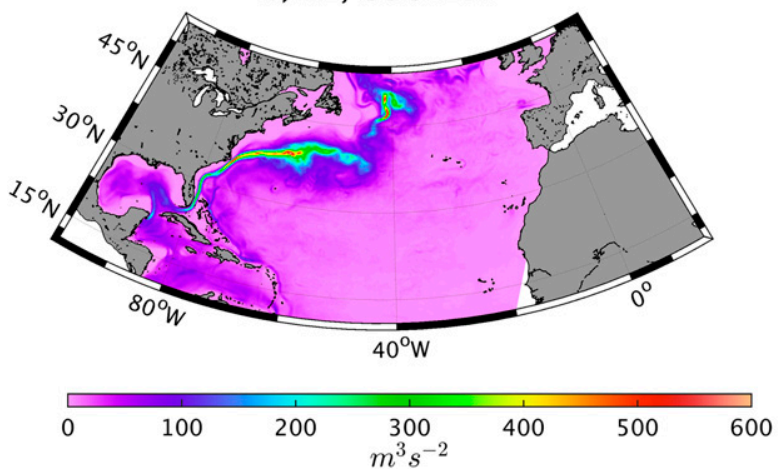

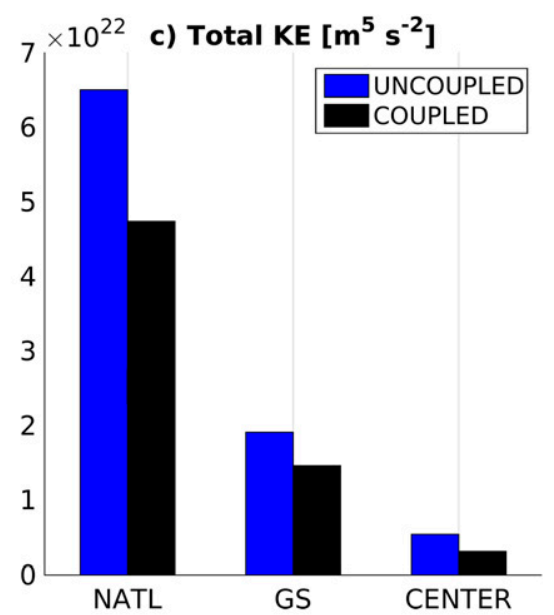

FIG. 4. Mean depth-integrated kinetic energy from (a) UNCOUPLED and (b) COUPLED. (c) Total depthintegrated KE overall the domain (NATL) and the GS and CENTER boxes indicated in (a) from UNCOUPLED (blue) and COUPLED (black). The current feedback, by reducing $F_{m} K_{m g}$, weakens the mean circulation The integrated $\mathrm{KE}$ is reduced by $27 \%$.

part of the gyre (including the Gulf of Mexico Loop Current) and the GS. COUPLED still overestimates $F_{m} K_{m g}$ with respect to the observation estimates; this could be due partly to models biases but also to the spatial resolution and smoothing used in AVISO. The $F_{m} K_{m g}$ reduction in COUPLED is consistent with the Scott and Xu (2009) findings. Using the observations, they suggest that ignoring the current feedback in the estimation of the surface stress leads to a systematic overestimation of $F_{m} K_{m g}$ of $10 \%-30 \%$. The overestimation of $F_{m} K_{m g}$ in UNCOUPLED compared to COUPLED is about $50 \%$, which is larger than the estimate by Scott and Xu (2009). However, although Scott and Xu (2009) uses the observations that by definition include all the feedback, Scott and $\mathrm{Xu}$ (2009) could not estimate the $F_{m} K_{m g}$ for a nonactive atmosphere that results in stronger oceanic currents. Figure 4 shows the depth-integrated KE for COUPLED and UNCOUPLED. The reduction of $F_{m} K_{m g}$ slows down the entire gyre circulation and hence reduces the total KE by $27 \%$. This is in agreement with Eden and Dietze (2009), Pacanowski (1987), and
Luo et al. (2005), who all found a significant reduction of the Southern Equatorial Current (SEC) and Equatorial Undercurrent induced by the current feedback to the surface stress. The slowing down of the gyreand hence the weakening of the geostrophic surface current (up to $0.3 \mathrm{~m} \mathrm{~s}^{-1}$, not shown)-explains the large reduction of $F_{m} K_{m g}$ from UNCOUPLED to COUPLED. A $F_{m} K_{m g}$ reduction equivalent to the Scott and Xu (2009) estimate can be computed using the surface geostrophic surface currents from COUPLED and the surface stress from COUPLED or UNCOUPLED (i.e., with or without current feedback). In that case, ignoring the influence of the surface current on the surface stress (as UNCOUPLED does) leads to an overestimation of $F_{m} K_{m g}$ by $10 \%$, in good agreement with Scott and $\mathrm{Xu}$ (2009). Finally, the net transport estimated over the North Atlantic basin (de Verdière and Ollitrault 2016; Ollitrault and de Verdière 2014) from the ARGO and World Ocean Atlas data (Levitus et al. 2013), and from COUPLED and UNCOUPLED, is illustrated in Fig. 5. Consistent with the KE reduction, the net transport is reduced with the current 

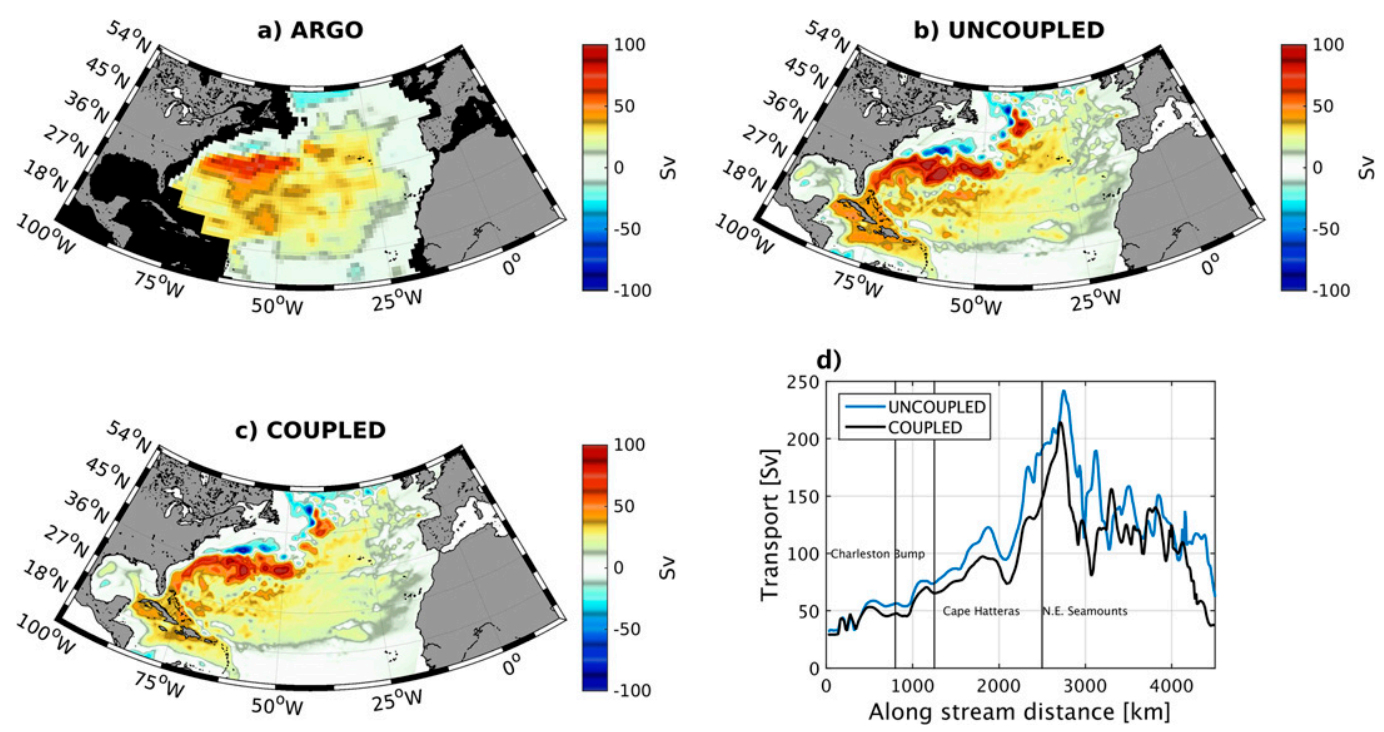

FIG. 5. Mean net transport estimated from (a) ARGO and World Ocean Atlas (de Verdière and Ollitrault 2016) and from (b) UNCOUPLED and (c) COUPLED. (d) Mean net transport estimated along the GS path. Consistent with a slowdown of the mean circulation, the net transport is reduced by the current feedback from UNCOUPLED to COUPLED, improving the realism of the simulation.

feedback, thus reducing the biases of the simulation with respect to the de Verdière and Ollitrault (2016) estimates. In particular, the transport is reduced along the GS path, especially after the GS separation at Cape Hatteras.

\section{Eddy kinetic energy and mean pathway of energy from the ocean to the atmosphere}

The surface geostrophic EKE is estimated using the daily geostrophic surface current perturbations from the experiments and from AVISO (Fig. 6). The EKE is larger in the Caribbean Sea, the Gulf of Mexico, and along the GS path, in good agreement with the literature (Reverdin et al. 2003; Penduff et al. 2004). UNCOUPLED has a larger EKE than AVISO. This is partly explained by the smoothing used in AVISO. There are eddies in the real ocean that have scales smaller than can be resolved by the AVISO dataset (e.g., Chelton and Schlax 2003). However, a significant portion of the discrepancy is due to the lack of current feedback in UNCOUPLED. UNCOUPLED does not represent the eddy killing process induced by the current feedback (Fig. 7). From COUPLED to UNCOUPLED, the EKE is reduced by $29 \%$, and, in particular, it decreases the EKE and its spread along the GS path (Figs. 6d,e,f).

Two pathways of energy can explain the reduction of EKE from UNCOUPLED to COUPLED. First, there is a reduction of the available mean energy at basin scale due to the current feedback-induced reduction of $F_{m} K_{m g}$. This produces a reduction of the barotropic conversion from mean kinetic energy to $\operatorname{EKE}\left(K_{m} K_{e}\right)$ and the baroclinic conversion from the eddy available potential energy to EKE $\left(P_{e} K_{e}\right)$. However, in agreement with Eden and Dietze (2009), the changes in $K_{m} K_{e}$ and $P_{e} K_{e}$ do not explain the EKE differences from UNCOUPLED to COUPLED (not shown). The second pathway is the deflection of energy from the oceanic geostrophic currents (eddies) to the atmosphere. Figure 5 from Renault et al. (2016b) provides a cartoon explanation of the geostrophic sink through $F_{e} K_{e g}$. Over an eddy there is a reduction of the positive $F_{e} K_{e g}$ (i.e., less energy input to the ocean) and an increase of the negative $F_{e} K_{e g}$ (i.e., more energy transfer from the ocean to the atmosphere), leading to a net negative $F_{e} K_{e g}$ over an eddy. In Fig. 7, $F_{e} K_{e g}$ is estimated from both the simulations and independently from the geostrophic currents from AVISO and the surface stress from a QuikSCAT product (Bentamy and Fillon 2012) over the period 2000-04 (similar results are obtained using the period 2000-09). Along the coast the wind perturbations induce an offshore Ekman surface current and an oceanic geostrophic coastal jet (e.g., Renault et al. 2012) that flow partially in the same direction as the wind, inducing a positive $F_{e} K_{e g}$ (Renault et al. 2016b). In agreement with the literature (e.g., Renault et al. 2016b; Scott and Xu 2009), the observations also reveal a pathway of energy from the ocean to the atmosphere over the full gyre and in particular over the GS. This large-scale pathway of energy from 
a) EKE, AVISO
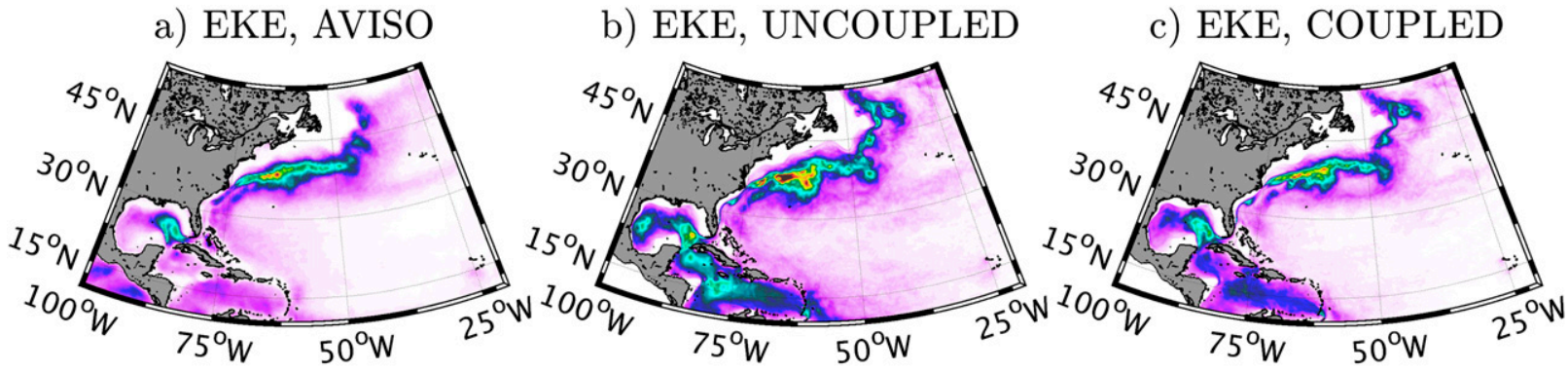

1000

1500

$\mathrm{cm}^{2} \mathrm{~s}^{-2} \quad 2500$

e) EKE, UNCOUPLED
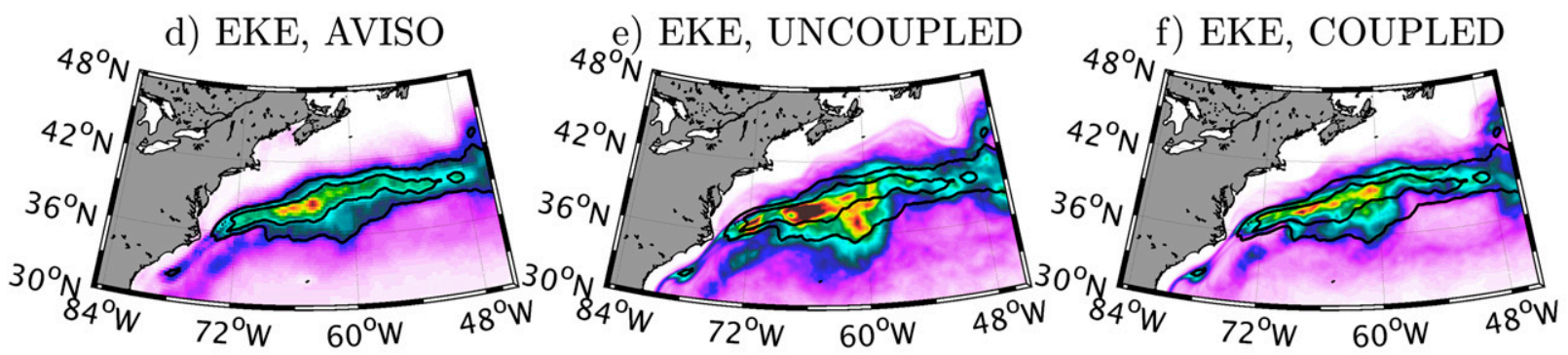

f) EKE, COUPLED

$3000 \quad 3500 \quad 4000$

\begin{tabular}{lllcrrrr}
\hline 500 & 1000 & 1500 & $\begin{array}{c}2000 \\
\mathrm{~cm}^{2} \mathrm{~s}^{-2}\end{array}$ & 2500 & 3000 & 3500 & 4000
\end{tabular}

FIG. 6. EKE for the period 2000-04 from AVISO, UNCOUPLED, and COUPLED for the (a)-(c) North Atlantic and around the (d)-(f) GS separation. The black contours in (d)-(f) depict the mean EKE from AVISO (one contour each $1000 \mathrm{~cm}^{2} \mathrm{~s}^{-2}$ ). The current feedback causes a drastic reduction of the EKE by $30 \%$. In particular, it limits the propagation of eddies far from the mean GS path.

the ocean to the atmosphere is induced by the current feedback. COUPLED has larger values of $F_{e} K_{e g}$ with respect to the observation estimate, again this is explained partly by model biases but also by the smoothing used in AVISO (e.g., Chelton and Schlax 2003). UNCOUPLED does not reproduce the negative $F_{e} K_{e g}$ because it ignores the currents' influence on the atmosphere. As a result, in UNCOUPLED eddies are advected along the GS path, they are not dampened by the eddy killing mechanism, and they eventually detach and propagate westward (McWilliams 1985) toward Cape Hatteras where they can die, merge, and/or recirculate, which explains the UNCOUPLED overestimation of the EKE in the vicinity of Cape Hatteras. In COUPLED and in AVISO, eddies detach from the GS but are dampened by the eddy killing mechanism. COUPLED reproduces the negative $F_{e} K_{e g}$, only with larger values. This is most likely partially explained by the smoothing used in AVISO. In COUPLED the larger the EKE (and the wind) is, the larger the deflection of energy from the ocean to the atmosphere.
The main driver of the EKE reduction is this partway of energy.

\section{Mean Gulf Stream intensity, path, and separation}

The current feedback causes a slowdown of the mean circulation and a drastic weakening of the EKE. The aim of this section is to address the changes on the GS transport intensity, path, and separation induced by the current feedback. Figure 8 shows an estimate of the mean GS path and its root-mean-square (RMS) using the mean geostrophic current amplitude from AVISO, UNCOUPLED, and COUPLED. The current feedback has a strong influence on the GS. In general the reduction of the transport improves the realism of the circulation. The first effect is a reduction of the GS depth-integrated KE (Fig. 4; by 20\%), which is in good agreement with the slowdown of the gyre and the reduction of the EKE that induces a weakening of the mesoscale recirculation. Two regions can be distinguished: the South Atlantic Bight 

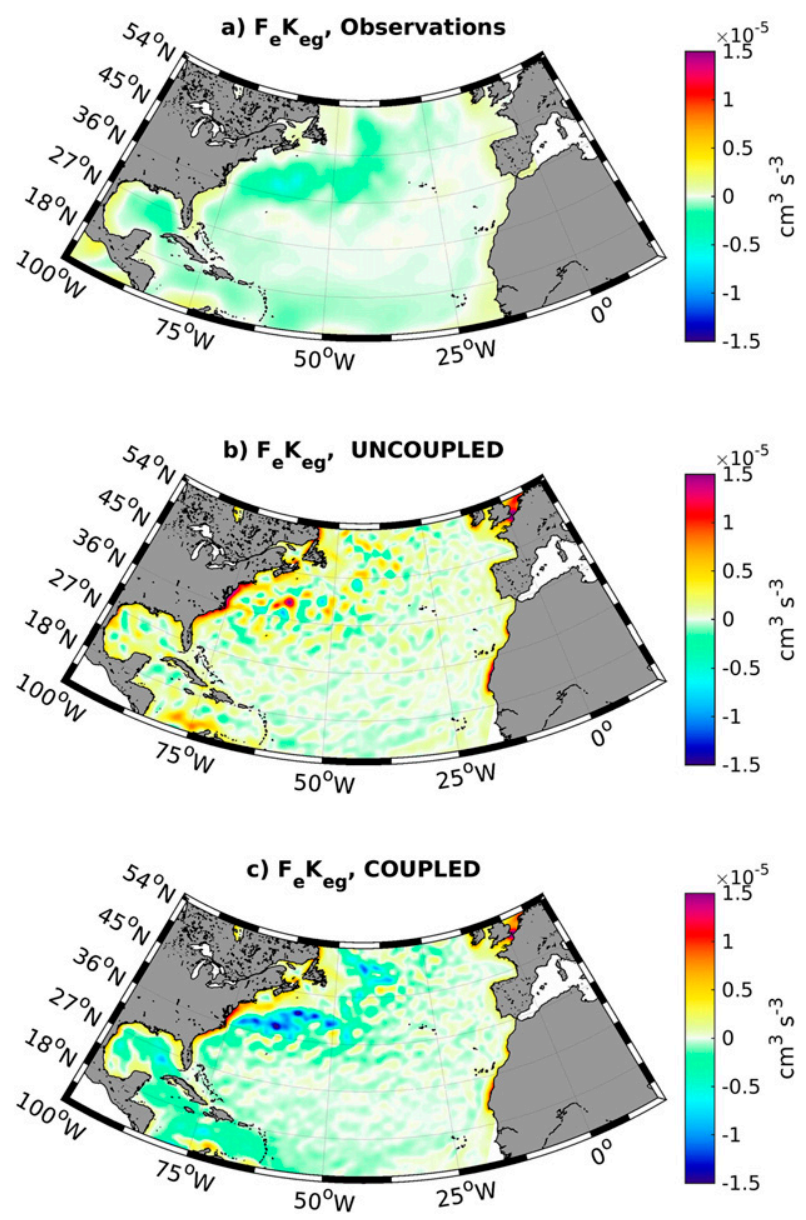

FIG. 7. Mean geostrophic eddy wind work $\left(F_{e} K_{e g}\right)$ from the (a) observations, (b) UNCOUPLED, and (c) COUPLED for the period 2000-04, smoothed on three grid points. Consistent with former studies, there is a deflection of energy from the ocean to the atmosphere from the geostrophic currents (eddies). The current feedback to the atmosphere induces a large pathway of energy from the ocean to the atmosphere, which is the main driver of the EKE reduction (eddy killing).

$\left(30^{\circ}-36^{\circ} \mathrm{N}\right)$ and the region downstream of the GS separation at Cape Hatteras (from $36^{\circ} \mathrm{N}$ to $75^{\circ} \mathrm{W}$ ). In agreement with the observations, the GS flows northward along the South Atlantic Bight and is slightly deflected offshore at the location of the Charleston bump $\left(32^{\circ} \mathrm{N}\right)$ and then separates at Cape Hatteras in all the experiments. The net transport from the experiments is estimated through two keys sections: the Florida Strait, where Hamilton et al. (2005) estimate a net transport of $25 \mathrm{~Sv}\left(1 \mathrm{~Sv} \equiv 10^{6} \mathrm{~m}^{3} \mathrm{~s}^{-1}\right)$, and the Strait between the Florida coast and the Bahamas, where Cunningham et al. (2007) indicate a net transport of $31.3 \pm 3.3 \mathrm{~Sv}$. The net transport through the Florida Strait is weaker than the net transport through the strait between the Florida coast and the Bahamas due to the inflow transport through the Florida Strait and the input of about $2 \mathrm{~Sv}$ from the open ocean to the strait between the Florida coast and the Bahamas (Hamilton et al. 2005). Consistent with the previous findings, the current feedback causes a reduction of the transport. The net transport from UNCOUPLED and COUPLED through the Florida Strait is reduced from 30.2 to $25.6 \mathrm{~Sv}$ (Fig. 5d), improving the realism of the simulation. Between the Florida coast and the Bahamas, it is reduced from 34 to 29 Sv. However, both UNCOUPLED and COUPLED transports through that section are within the range of the net transport estimated by Cunningham et al. (2007).

In the observations (Figs. 8a,b), the separation of the GS at Cape Hatteras is characterized by a concave path and then by a very stable path postseparation. Those features are very difficult to represent in numerical oceanic models; the reasons are still elusive (Schoonover et al. 2016). UNCOUPLED, as the simulations in Schoonover et al. (2016), is able to represent the GS separation at Cape Hatteras; however, it is characterized by the presence of a standing eddy making its separation convex. Additionally, the postseparation region is characterized by a too large EKE (Fig. 6e) that induces a spatial spread of mean circulation (Figs. 4a, 8b) and too large a RMS of the geostrophic currents with respect to the observations (Fig. 8b). The current feedback strongly improves the GS separation and postseparation characteristics. In COUPLED, the GS has a concave separation at Cape Hatteras as in the observations (Fig. 8a). The spread of the mean circulation is reduced (Figs. 4b, 8a,b). The effect of the current feedback can also be highlighted using the mean sea surface height (SSH; Fig. 9). UNCOUPLED has three main biases: its SSH gradients are too strong (i.e., a too intense surface GS), the GS separation is characterized by the presence of a standing eddy and is therefore convex, and the postseparation is too unstable, with too large meanderings. COUPLED has weaker SSH gradients, a concave separation, and a straight postseparation path, without strong meandering. To our knowledge this is the first time a numerical simulation (without data assimilation) can reproduce such a feature (see, e.g., Schoonover et al. 2016).

The current feedback large-scale and local effects are potentially the two main drivers that explain the GS transport intensity reduction and the stabilization of the GS path and separation. To determine their respective impact, two additional uncoupled experiments were carried out using the smaller domain shown in Fig. 9. The first experiment, LOC_COUPLED, is forced at the boundaries by the large-scale fields from UNCOUPLED. It takes into account the oceanic surface current when estimating the surface stress. In that sense 

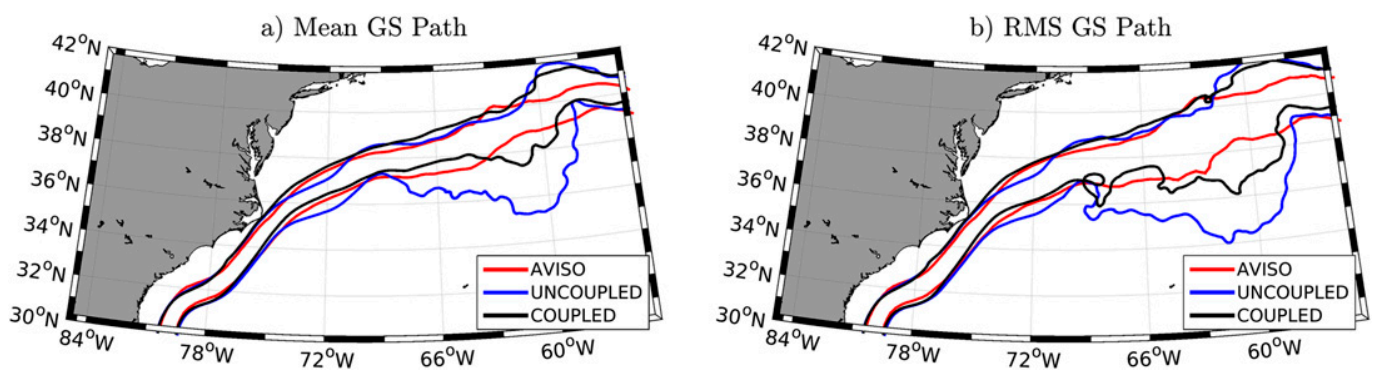

FIG. 8. (a) Mean path of the GS illustrated by the mean geostrophic currents estimated from AVISO and the simulations (contour of $0.6 \mathrm{~m} \mathrm{~s}^{-1}$ ) for the period 2000-04. (b) The GS path stability estimated by the RMS of the geostrophic currents from AVISO and the experiments (contour of $0.6 \mathrm{~m} \mathrm{~s}^{-1}$ ) for the period 2000-04. From UNCOUPLED to COUPLED there is a narrowing of the GS path and a stabilization. Additionally, the concave GS separation is well reproduced by COUPLED, contrary to UNCOUPLED, which has too important meandering postseparation.

it does not have the large-scale current feedback effect (i.e., the slowing down of the mean circulation) but has the local current feedback effect. The second experiment REM_COUPLED is forced at the boundaries by the large circulation from COUPLED and does not take into account the current when estimating the surface stress. In that sense, REM_COUPLED does have the large-scale effect of the current feedback but does not have the local effect (i.e., eddy killing). Because LOC_COUPLED is run without the atmospheric response, the eddy killing effect is slightly overestimated (Renault et al. 2016b). However, because the aim of that simulation is to highlight the role of the local effect on the GS characteristic, this presence or lack of

a) AVISO

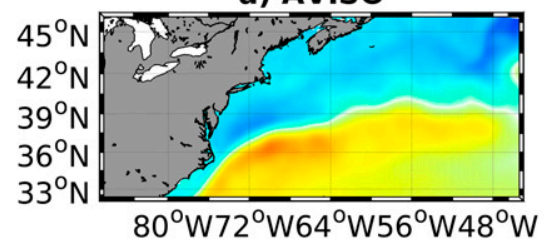

b) UNCOUPLED

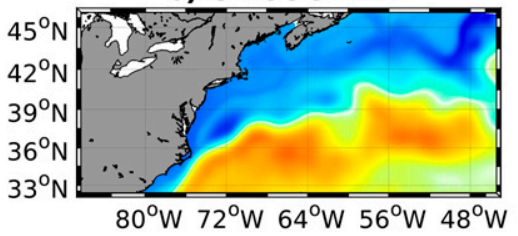

d) LOC COUPLED

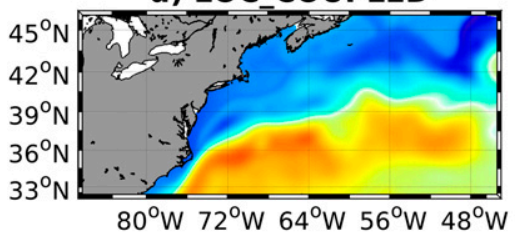

\section{c) REM_COUPLED}

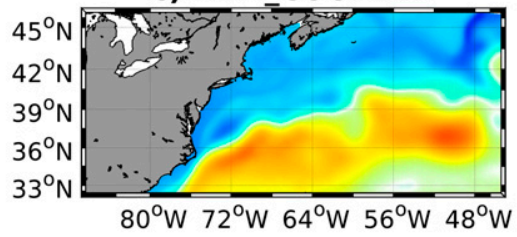

e) COUPLED

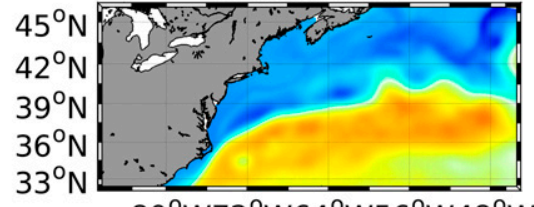

$80^{\circ} \mathrm{W} 72^{\circ} \mathrm{W} 64^{\circ} \mathrm{W} 56^{\circ} \mathrm{W} 48^{\circ} \mathrm{W}$

$\begin{array}{lllllllllll}-1 & -0.8 & -0.6 & -0.4 & -0.2 & 0 & 0.2 & 0.4 & 0.6 & 0.8 & 1\end{array}$

FIG. 9. Mean SSH from (a) AVISO, (b) UNCOUPLED, (c) REM_COUPLED, (d) LOC_COUPLED, and (e) COUPLED. The current feedback improves the realism of the mean SSH and its gradient. From UNCOUPLED to COUPLED, there is a reduction of the SSH gradient and, with good agreement with AVISO, a stabilization of the postseparation. The local effect of the current feedback, that is, the eddy killing is the main driver of the GS stabilization and improvement. Even with the large-scale conditions from UNCOUPLED, LOC_COUPLED has a stable path and a concave separation, whereas REM_COUPLED, due to its lack of current feedback, is characterized by a too large meandering. 


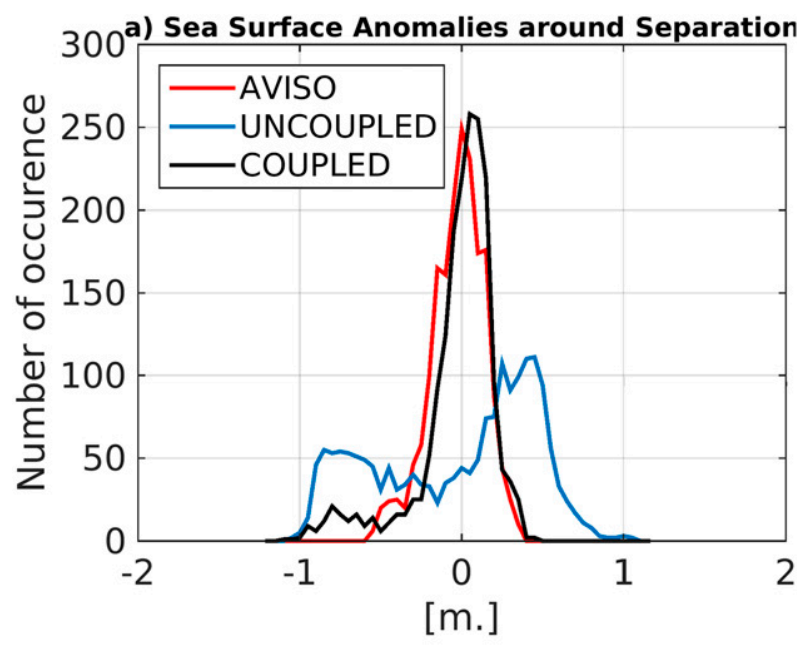

b) Snapshot of Sea Level Anomalies, UNCOUPLED

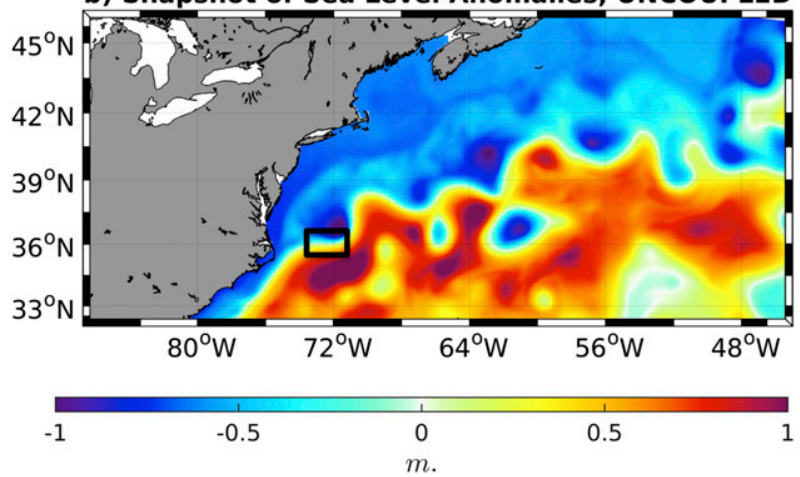

FIG. 10. (a) Histogram of SLA in the black box [indicated in (b)] from AVISO (red), UNCOUPLED (blue), and COUPLED (black) for the period 2000-04. (b) Snapshot of the SLA from UNCOUPLED. In UNCOUPLED, the presence of a too large mesoscale activity in the vicinity of the GS separation at Cape Hatteras destabilizes the mean circulation.

atmospheric response will not change the conclusion. Figure 9 shows the mean SSH from AVISO, COUPLED, UNCOUPLED, LOC_COUPLED, and REM_COUPLED. LOC_COUPLED, despite too strong SSH gradients, is characterized by a concave separation and a stable postseparation as COUPLED (Figs. 9a,d). REM_COUPLED, despite similar SSH gradients to COUPLED, does not present a concave GS separation at Cape Hatteras nor a stable GS postseparation. The additional experiments indicate that the large-scale effect is important as it modulates the intensity and the shape of the GS postseparation. However, the local effect, through the eddy killing, is essential to stabilize the GS separation and its behavior postseparation, allowing its separation to be concave. That also explains why the GS separation and postseparation are very stable in the observations despite an important interannual variability of its intensity. Finally, Fig. 10a depicts the histogram of the sea level anomalies (SLA) at the separation from AVISO, COUPLED, and UNCOUPLED. In both AVISO and COUPLED, the SLA distribution is characterized by a large kurtosis (5 and 6 , respectively) and a narrow distribution. UNCOUPLED has a weaker kurtosis (2.7, negative excess kurtosis of -0.3 ), which is a manifestation of the larger EKE activity that causes the GS convex separation (negative SLA) and instability. The mean convex separation in UNCOUPLED is not a stable feature and is induced by the mesoscale activity. As shown in Fig. 10b, by ignoring the influence of the current feedback to the atmosphere, UNCOUPLED allows eddies to propagate westward and then die or recirculate near Cape Hatteras, making the GS separation convex.

\section{Discussion and conclusions}

Using ocean-atmosphere coupled and uncoupled simulations, we assess the role of the current feedback through the surface mean and eddy wind work, the energy transfer between the atmosphere to the ocean, and its consequences for the mean circulation in the North Atlantic basin and, more specifically, the Gulf Stream (GS) mean characteristics. We show that the current feedback has two main effects: a large-scale effect and a local effect. In good agreement with former studies, we first show that the current feedback attenuates the mean wind work by reducing the surface stress and consequently diminishes the mean transfer of energy from the atmosphere to the ocean. This has the effect of slowing down the full North Atlantic Gyre and narrowing the GS. Consistent with previous studies, we show that the local effect acts as an eddy killer. As shown by Renault et al. (2016b), the current feedback induces a surface stress curl opposite to the current vorticity that deflects energy from the geostrophic current into the atmosphere and dampens eddies. It causes a mean pathway of energy from the ocean to the atmosphere. The larger the EKE is, the larger the sink of energy. Consequently, the current feedback drastically reduces the EKE and limits the propagation of eddies.

Numerical models have difficulty in representing the GS path, separation characteristics, and stability. Although the GS transport intensity presents an interannual variability, the path and the separation remain very stable through the years. This feature was not well represented in numerical models (Schoonover et al. 2016). We show, using a particular ocean model, this may be due to the lack of current feedback to the atmosphere. The current feedback controls the GS transport intensity and its path and separation through 
both its large-scale and local effect. The slowdown of the gyre induces a less intense and narrower GS, whereas the eddy killing effect causes a concave separation at Cape Hatteras that is consistent with the observations. It also induces a straight and stable mean GS path postseparation, which is in good agreement with the observations. However, if the GS transport intensity is erroneously too strong, it could generate too large a level of EKE. In such a case, the eddy killing effect would not be sufficient to stabilize the GS path. In general, the current feedback allows a more realistic simulation in terms of surface stress, mean transports, and mean SSH. Those results should be tested by comparisons with different numerical models as in, for example, Schoonover et al. (2016).

This study also raises the question of the convergence of the numerical models and of the current feedback effect. By increasing the spatial resolution, the EKE and the total KE may increase. This should increase the mean wind work, but, on the other hand, the current feedback should adjust to that increase and reduce it. Similarly, the EKE increase will induce a larger deflection of energy from the ocean to the atmosphere, which will dampen it.

The reduction of the mean energy from the atmosphere to the ocean is in agreement with the findings of Scott and Xu (2009) and Hughes and Wilson (2008). Here, we found that the work of the mean wind on the mean oceanic circulation is overestimated by $50 \%$ if the current feedback is not taken into account when computing the surface wind stress. This large overestimate is due to the overestimate of the surface stress and due to the oceanic response. Scott and Xu (2009) use observations that by definition include all the ocean-atmosphere feedbacks. However, they could not estimate the $F_{m} K_{m g}$ for a nonactive atmosphere, which results in stronger oceanic currents. By using the oceanic circulation from COUPLED [to ignore the oceanic response and thus be comparable to the Scott and Xu (2009) estimates] and the surface stress with and without current feedback, we found that the lack of current feedback in the estimate of the surface stress leads to overestimation of $F_{m} K_{m g}$ by $10 \%$, which is consistent with the Scott and $\mathrm{Xu}$ (2009) estimate. Finally, as in Renault et al. (2016b), the current feedback has an impact on the wind itself. From an oceanic point of view, it partially counteracts the effect on the surface stress, partly reenergizing the ocean. However, from an atmospheric point of view, it remains weak compared to the wind speed intensity (up to $0.3 \mathrm{~m} \mathrm{~s}^{-1}$ over the GS, not shown).

In summary, ocean-atmosphere models should take into account the current feedback to have a realistic representation of the transfer of energy between the atmosphere and the ocean and thus of the mean circulation and the EKE. These findings should be true for other regions and other intense western boundary currents such as the Kuroshio Current and the Agulhas Current and its retroflection. Not only would this have a local impact but also impacts on other regions (e.g., the Benguela upwelling through the Agulhas leakage and ring propagation would be weakened by the current feedback).

Acknowledgments. We appreciate support from the Office of Naval Research (ONR N00014-12-1-0939), the National Science Foundation (OCE-1419450), the California Ocean Protection Council Grant C0100400 ("Integrated modeling assessments and projections for the California Current System"), and the Bureau of Ocean Energy Management (Grant M14AC00021). This work used the Extreme Science and Engineering Discovery Environment (XSEDE) and Yellowstone (NCAR) computers. The authors thank two anonymous reviewers for their comments.

\section{REFERENCES}

Beckmann, A., and D. B. Haidvogel, 1993: Numerical simulation of flow around a tall isolated seamount. Part I: Problem formulation and model accuracy. J. Phys. Oceanogr., 23, 1736-1753, doi:10.1175/1520-0485(1993)023<1736:NSOFAA > 2.0.CO;2.

Bentamy, A., and D. C. Fillon, 2012: Gridded surface wind fields from Metop/ASCAT measurements. Int. J. Remote Sens., 33, 1729-1754, doi:10.1080/01431161.2011.600348.

Bryan, F. O., M. W. Hecht, and R. D. Smith, 2007: Resolution convergence and sensitivity studies with North Atlantic circulation models. Part I: The western boundary current system. Ocean Modell., 16, 141-159, doi:10.1016/j.ocemod.2006.08.005.

Carton, J. A., and B. S. Giese, 2008: A reanalysis of ocean climate using Simple Ocean Data Assimilation (SODA). Mon. Wea. Rev., 136, 2999-3017, doi:10.1175/2007MWR1978.1.

Chassignet, E. P., and D. P. Marshall, 2008: Gulf Stream separation in numerical ocean models. Ocean Modeling in an Eddying Regime, Geophys. Monogr., Vol. 177, 39-61, doi:10.1029/ $177 \mathrm{GM} 05$.

Chelton, D. B., and M. G. Schlax, 2003: The accuracies of smoothed sea surface height fields constructed from tandem satellite altimeter datasets. J. Atmos. Oceanic Technol., 20, 1276-1302, doi:10.1175/1520-0426(2003)020<1276:TAOSSS > 2.0.CO;2.

,,-- M. H. Freilich, and R. F. Milliff, 2004: Satellite measurements reveal persistent small-scale features in ocean winds. Science, 303, 978-983, doi:10.1126/science.1091901.

,-- , and R. M. Samelson, 2007: Summertime coupling between sea surface temperature and wind stress in the California Current System. J. Phys. Oceanogr., 37, 495-517, doi:10.1175/JPO3025.1.

Chou, M.-D., and M. J. Suarez, 1999: A solar radiation parameterization for atmospheric studies. NASA Tech. Rep. NASA/ TM-1999-104606, 51 pp. [Available online at https:/gmao. gsfc.nasa.gov/pubs/docs/Chou136.pdf.]

Cornillon, P., and K. Park, 2001: Warm core ring velocities inferred from NSCAT. Geophys. Res. Lett., 28, 575-578, doi:10.1029/ 2000 GL011487. 
Cunningham, S. A., and Coauthors, 2007: Temporal variability of the Atlantic meridional overturning circulation at $26.5^{\circ} \mathrm{N}$. Science, 317, 935-938, doi:10.1126/science.1141304.

Dawe, J. T., and L. Thompson, 2006: Effect of ocean surface currents on wind stress, heat flux, and wind power input to the ocean. Geophys. Res. Lett., 33, L09604, doi:10.1029/ 2006 GL025784.

Debreu, L., P. Marchesiello, P. Penven, and G. Cambon, 2012: Two-way nesting in split-explicit ocean models: Algorithms, implementation and validation. Ocean Modell., 49-50, 1-21, doi:10.1016/j.ocemod.2012.03.003.

de Verdière, C. A., and M. Ollitrault, 2016: A direct determination of the World Ocean barotropic circulation. J. Phys. Oceanogr., 46, 255-273, doi:10.1175/JPO-D-15-0046.1.

Dewar, W. K., and G. R. Flierl, 1987: Some effects of the wind on rings. J. Phys. Oceanogr., 17, 1653-1667, doi:10.1175/ 1520-0485(1987)017<1653:SEOTWO>2.0.CO;2.

Ducet, N., P.-Y. Le Traon, and G. Reverdin, 2000: Global high-resolution mapping of ocean circulation from TOPEX/ Poseidon and ERS-1 and -2. J. Geophys. Res., 105, $19477-$ 19 498, doi:10.1029/2000JC900063.

Duhaut, T. H., and D. N. Straub, 2006: Wind stress dependence on ocean surface velocity: Implications for mechanical energy input to ocean circulation. J. Phys. Oceanogr., 36, 202-211, doi:10.1175/JPO2842.1.

Eden, C., and H. Dietze, 2009: Effects of mesoscale eddy/wind interactions on biological new production and eddy kinetic energy. J. Geophys. Res., 114, C05023, doi:10.1029/ 2008JC005129.

Fairall, C., E. F. Bradley, J. Hare, A. Grachev, and J. Edson, 2003: Bulk parameterization of air-sea fluxes: Updates and verification for the COARE algorithm. J. Climate, 16, 571-591, doi:10.1175/1520-0442(2003)016<0571:BPOASF>2.0.CO;2.

Gula, J., M. J. Molemaker, and J. C. McWilliams, 2015: Gulf Stream dynamics along the southeastern U.S. seaboard. J. Phys. Oceanogr., 45, 690-715, doi:10.1175/JPO-D-14-0154.1.

Hamilton, P., J. C. Larsen, K. D. Leaman, T. N. Lee, and E. Waddell, 2005: Transports through the Straits of Florida. J. Phys. Oceanogr., 35, 308-322, doi:10.1175/JPO-2688.1.

Han, J., and H.-L. Pan, 2011: Revision of convection and vertical diffusion schemes in the NCEP global forecast system. Wea. Forecasting, 26, 520-533, doi:10.1175/WAF-D-10-05038.1.

Hogg, A. M. C., W. K. Dewar, P. Berloff, S. Kravtsov, and D. K. Hutchinson, 2009: The effects of mesoscale ocean-atmosphere coupling on the large-scale ocean circulation. J. Climate, 22, 4066-4082, doi:10.1175/2009JCLI2629.1.

Hong, S.-Y., and J.-O. J. Lim, 2006: The WRF single-moment 6-class microphysics scheme (WSM6). J. Korean Meteor. Soc., 42, 129-151.

Hughes, C. W., and C. Wilson, 2008: Wind work on the geostrophic ocean circulation: An observational study of the effect of small scales in the wind stress. J. Geophys. Res., 113, C02016, doi:10.1029/2007JC004371.

Jousse, A., A. Hall, F. Sun, and J. Teixeira, 2016: Causes of WRF surface energy fluxes biases in a stratocumulus region. Climate Dyn., 46, 571-584, doi:10.1007/s00382-015-2599-9.

Large, W. G., J. C. McWilliams, and S. C. Doney, 1994: Oceanic vertical mixing: A review and a model with a nonlocal boundary layer parameterization. Rev. Geophys., 32, 363-404, doi:10.1029/94RG01872.

Lemarié, F., J. Kurian, A. F. Shchepetkin, M. J. Molemaker, F. Colas, and J. C. McWilliams, 2012: Are there inescapable issues prohibiting the use of terrain-following coordinates in climate models? Ocean Modell., 42, 57-79, doi:10.1016/ j.ocemod.2011.11.007.

Levitus, S., and Coauthors, 2013: The world ocean database. Data Sci. J., 12, WDS229-WDS234, doi:10.2481/dsj.WDS-041.

Luo, J.-J., S. Masson, E. Roeckner, G. Madec, and T. Yamagata, 2005: Reducing climatology bias in an ocean-atmosphere CGCM with improved coupling physics. J. Climate, 18, 2344-2360, doi:10.1175/JCLI3404.1.

Marchesiello, P., J. C. McWilliams, and A. Shchepetkin, 2001: Open boundary conditions for long-term integration of regional oceanic models. Ocean Modell., 3, 1-20, doi:10.1016/ S1463-5003(00)00013-5.

McCarthy, G., and Coauthors, 2012: Observed interannual variability of the Atlantic meridional overturning circulation at $26.5^{\circ}$ N. Geophys. Res. Lett., 39, L19609, doi:10.1029/ 2012GL052933.

McWilliams, J. C., 1985: Submesoscale, coherent vortices in the ocean. Rev. Geophys., 23, 165-182, doi:10.1029/RG023i002p00165.

Minobe, S., A. Kuwano-Yoshida, N. Komori, S.-P. Xie, and R. J. Small, 2008: Influence of the Gulf Stream on the troposphere. Nature, 452, 206-209, doi:10.1038/nature06690.

Nakanishi, M., and H. Niino, 2006: An improved Mellor-Yamada level-3 model: Its numerical stability and application to a regional prediction of advection fog. Bound.-Layer Meteor., 119, 397-407, doi:10.1007/s10546-005-9030-8.

Ollitrault, M., and A. C. de Verdière, 2014: The ocean general circulation near 1000-m depth. J. Phys. Oceanogr., 44, 389409, doi:10.1175/JPO-D-13-030.1.

Pacanowski, R., 1987: Effect of equatorial currents on surface stress. J. Phys. Oceanogr., 17, 833-838, doi:10.1175/ 1520-0485(1987)017<0833:EOECOS >2.0.CO;2.

Park, H., D. Lee, W.-P. Jeon, S. Hahn, J. Kim, J. Kim, J. Choi, and H. Choi, 2006: Drag reduction in flow over a twodimensional bluff body with a blunt trailing edge using a new passive device. J. Fluid Mech., 563, 389-414, doi:10.1017/ S0022112006001364.

Penduff, T., B. Barnier, W. K. Dewar, and J. J. O'Brien, 2004: Dynamical response of the oceanic eddy field to the North Atlantic Oscillation: A model-data comparison. J. Phys. Oceanogr., 34, 2615-2629, doi:10.1175/JPO2618.1.

Perlin, N., E. D. Skyllingstad, R. M. Samelson, and P. L. Barbour, 2007: Numerical simulation of air-sea coupling during coastal upwelling. J. Phys. Oceanogr., 37, 2081-2093, doi:10.1175/ JPO3104.1.

Renault, L., and Coauthors, 2012: Upwelling response to atmospheric coastal jets off central Chile: A modeling study of the October 2000 event. J. Geophys. Res., 117, C02030, doi:10.1029/2011JC007446.

_ - A. Hall, and J. C. McWilliams, 2016a: Orographic shaping of US West Coast wind profiles during the upwelling season. Climate Dyn., 46, 273-289, doi:10.1007/s00382-015-2583-4

_ M. J. Molemaker, J. C. McWilliams, A. F. Shchepetkin, F. Lemarié, D. Chelton, S. Illig, and A. Hall, 2016b: Modulation of wind work by oceanic current interaction with the atmosphere. J. Phys. Oceanogr., 46, 1685-1704, doi:10.1175/ JPO-D-15-0232.1.

Reverdin, G., P. Niiler, and H. Valdimarsson, 2003: North Atlantic Ocean surface currents. J. Geophys. Res., 108, 3002, doi:10.1029/2001JC001020.

Risien, C. M., and D. B. Chelton, 2008: A global climatology of surface wind and wind stress fields from eight years of QuikSCAT scatterometer data. J. Phys. Oceanogr., 38, 23792413, doi:10.1175/2008JPO3881.1. 
Saha, S., and Coauthors, 2010: The NCEP climate forecast system reanalysis. Bull. Amer. Meteor. Soc., 91, 1015-1057, doi:10.1175/2010BAMS3001.1.

Sandwell, D. T., and W. H. F. Smith, 1997: Marine gravity anomaly from Geosat and ERS 1 satellite altimetry. J. Geophys. Res., 102, 10 039-10 054, doi:10.1029/96JB03223.

Schoonover, J., and Coauthors, 2016: North Atlantic barotropic vorticity balances in numerical models. J. Phys. Oceanogr., 46, 289-303, doi:10.1175/JPO-D-15-0133.1.

Scott, R. B., and Y. Xu, 2009: An update on the wind power input to the surface geostrophic flow of the World Ocean. Deep-Sea Res. I, 56, 295-304, doi:10.1016/j.dsr.2008.09.010.

Seo, H., A. J. Miller, and J. R. Norris, 2016: Eddy-wind interaction in the California Current System: Dynamics and impacts. J. Phys. Oceanogr., 46, 439-459, doi:10.1175/JPO-D-15-0086.1.

Shchepetkin, A. F., 2015: An adaptive, Courant-numberdependent implicit scheme for vertical advection in oceanic modeling. Ocean Modell., 91, 38-69, doi:10.1016/ j.ocemod.2015.03.006.

_ and J. C. McWilliams, 2005: The Regional Oceanic Modeling System (ROMS): A split-explicit, free-surface, topographyfollowing-coordinate oceanic model. Ocean Modell., 9, 347404, doi:10.1016/j.ocemod.2004.08.002.

_ , and 2 2009: Correction and commentary for "Ocean forecasting in terrain-following coordinates: Formulation and skill assessment of the regional ocean modeling system" by Haidvogel et al., J. Comp. Phys. 227, pp. 3595-3624. J. Comput. Phys., 228, 8985-9000, doi:10.1016/j.jcp.2009.09.002.
Skamarock, W. C., and Coauthors, 2008: A description of the Advanced Research WRF version 3. NCAR Tech. Note NCAR/TN-475+STR, 113 pp., doi:10.5065/D68S4MVH.

Small, R., and Coauthors, 2008: Air-sea interaction over ocean fronts and eddies. Dyn. Atmos. Oceans, 45, 274-319, doi:10.1016/j.dynatmoce.2008.01.001.

Spall, M. A., 1996: Dynamics of the Gulf Stream/deep western boundary current crossover. Part I: Entrainment and recirculation. J. Phys. Oceanogr., 26, 2152-2168, doi:10.1175/ 1520-0485(1996)026<2152:DOTGSW > 2.0.CO;2.

_ 2007: Midlatitude wind stress-sea surface temperature coupling in the vicinity of oceanic fronts. J. Climate, 20, 37853801, doi:10.1175/JCLI4234.1.

Stern, M. E., 1975: Ocean Circulation Physics. Academic Press, $246 \mathrm{pp}$

Talandier, C., and Coauthors, 2014: Improvements of simulated western North Atlantic current system and impacts on the AMOC. Ocean Modell., 76, 1-19, doi:10.1016/j.ocemod.2013.12.007.

Valcke, S., 2013: The OASIS3 coupler: A European climate modelling community software. Geosci. Model Dev., 6, 373388, doi:10.5194/gmd-6-373-2013.

von Storch, J.-S., H. Sasaki, and J. Marotzke, 2007: Wind-generated power input to the deep ocean: An estimate using a $1 / 10^{\circ}$ general circulation model. J. Phys. Oceanogr., 37, 657-672, doi:10.1175/JPO3001.1.

Wunsch, C., 1998: The work done by the wind on the oceanic general circulation. J. Phys. Oceanogr., 28, 2332-2340, doi:10.1175/1520-0485(1998)028<2332:TWDBTW>2.0.CO;2. 